\title{
Dynamics of culling for Jersey, Holstein, and Jersey $\times$ Holstein crossbred cows in large multibreed dairy herds
}

\author{
P. J. Pinedo, ${ }^{1}$ A. Daniels, $\nmid$ J. Shumaker, $\neq$ and A. De Vries $\S$ \\ ${ }^{*}$ Texas A\&M AgriLife Research \& Extension Center, College of Veterinary Medicine and Biomedical Sciences, Texas A\&M University System, \\ Amarillo 79106 \\ †Circle H Headquarters LLC, Dalhart, TX 79022 \\ ¥Magnolia Veterinary Services, Amarillo, TX 79119 \\ §Department of Animal Sciences, University of Florida, Gainesville 32611
}

\section{ABSTRACT}

The objective of this observational study was to describe and compare the dynamics of reason-specific culling risk for the genetic groups Jerseys (JE), Holsteins $(\mathrm{HO})$, and Jersey $\times$ Holstein crossbreds $(\mathrm{JH})$, considering parity, stage of lactation, and milk yield, among other variables, in large multibreed dairy herds in Texas. The secondary objective was to analyze the association between survival and management factors, such as breeding and replacement policies, type of facilities, and use of cooling systems. After edits, available data included 202,384 lactations in 16 herds, ranging from 407 to 8,773 cows calving per year during the study period from 2007 to 2011. The distribution of lactation records by genetic group was 58 , 36 , and $6 \%$ for $\mathrm{HO}, \mathrm{JE}$, and $\mathrm{JH}$ crosses, respectively. Overall culling rates across breeds were 30.1, 32.1, and $35.0 \%$ for JH, JE, and HO, respectively. The dynamics of reason-specific culling were dependent on genetic group, parity, stage of lactation, milk yield, and herd characteristics. Early lactation was a critical period for "died" and "injury-sick" culling. The risk increased with days after calving for "breeding" and, in the case of HO, "low production" culling. Open cows had a 3.5 to 4.6 times greater risk for overall culling compared with pregnant cows. The odds of culling with reason "died" within the first $60 \mathrm{~d}$ in milk (DIM) were not significantly associated with genetic group. However, both JE and $\mathrm{JH}$ crosses had lower odds of live culling within the first 60 DIM compared with $\mathrm{HO}$ cows $(\mathrm{OR}=0.72$ and 0.82 , respectively). Other cow variables significantly associated with the risk of dying within the first $60 \mathrm{DIM}$ were cow relative 305-d mature equivalent (305ME) milk yield, parity, and season of calving. Significant herd-related variables for death included herd size and origin of replacements. In addition to genetic group,

Received November 5, 2013.

Accepted January 24, 2014.

${ }^{1}$ Corresponding author: ppinedo@ag.tamu.edu the risk of live culling within 60 DIM was associated with cow-relative 305ME milk yield, parity, and season of calving. Significant herd-related variables for live culling included herd-relative 305ME milk yield, herd size, type of facility, origin of replacement, and type of maternity. Overall, reason-specific culling followed similar patterns across DIM in the 3 genetic groups.

Key words: culling, death, Jersey, Holstein

\section{INTRODUCTION}

Culling is defined as the departure of cows from the herd because of sale, slaughter, salvage, or death (Fetrow et al., 2006). Both premature culling and mortality inflict financial losses to the dairy industry and are relevant animal welfare issues (Thomsen and Houe, 2006). In recent years, dairy cows have shown a trend for lower survival rates (Hare et al., 2006; Miller et al., 2008) and high involuntary culling rates are a concern on dairy farms (Weigel et al., 2003). Extra-farm factors significantly affecting decisions on culling include cost of replacements and milk and beef price (Hadley et al., 2006). At the farm level, culling is affected by management style, reproductive policy, type of facilities, level of production, herd size, and cattle breed, among other factors (Hadley et al., 2006; Hare et al., 2006; McConnel et al., 2008).

Several studies have analyzed the survival ability of different dairy breeds. Hare et al. (2006) reported that the survival rate to parity 2 for Holsteins (HO) first calving in 2000 was $74.3 \%$. Survival rates to parity 2 for other breeds were $71.8 \%$ for Ayrshires, $68.8 \%$ for Brown Swiss, $66.3 \%$ for Guernseys, and $76.2 \%$ for Jerseys (JE). Survival rate to parity 6 was $9.8 \%$ for $\mathrm{HO}$ and $15.6 \%$ for Jersey $\times$ Holstein $(\mathbf{J H})$ with first calving in 1996. Similarly, culling rates of 31.9 and $27.2 \%$ were estimated for HO and JE herds, respectively (Hadley et al., 2006). When survival to subsequent calving was compared between JH crossbred cows and HO, an advantage of 8.6 and $14.4 \%$ for a second and third calving in crossbred cows, respectively, was observed (Heins et al., 2012). 
Herds using a single breed are more representative of the US dairy industry. Multibreed herds are less common, but provide the opportunity for comparison of breed performance and survival, as individuals are under a common environment and management (Garcia-Peniche et al., 2006). The dairy industry in the Texas panhandle has exhibited sustained growth in the last decades, favoring large herds with cows housed in freestall barns and dry-lots. In some areas, the proximity to cheese-processing plants has stimulated the introduction of JE cattle, resulting in several herds where $\mathrm{HO}, \mathrm{JE}$, and their crosses are managed under the same systems.

Previous studies have investigated the dynamics of culling by different causes in dairy herds (Bascom and Young, 1998; Smith et al., 2000; Hadley et al., 2006; Pinedo et al., 2010). However, recent studies describing the risk for reason-specific culling in different types of cattle in multibreed commercial herds are scarce. It is presumable that the risk of reason-specific culling will vary depending on each particular breed and may be associated differently by multiple factors, such as stage of lactation, parity, pregnancy, season, herd characteristics, and other concurrent conditions affecting individual cows. Nevertheless, the potential effect of these and other factors on the risk of culling for specific reasons in JE, HO, and their crosses, managed under the same conditions in large commercial herds in Texas, has not been quantified. Consequently, the main objective of this observational study was to describe and compare the dynamics of reason-specific culling risk for JE, HO, and their crosses, considering parity, stage of lactation, milk yield, and herd characteristics in large multibreed dairy herds in Texas. The secondary objective was to analyze the association between management factors, such as type of facility (dry-lot vs. freestall), breeding (heat detection or synchronization of ovulation programs), and replacement policies and survival.

\section{MATERIALS AND METHODS}

\section{Study Population}

The current study explored risk factors for culling through analysis of lactation records from large multibreed herds in Texas and was restricted to JE, HO, and JH crossbred cows. A convenience sample of herds was selected based on the authors' contacts with farms, the presence of at least 2 of the genetic groups (JE, HO, and $\mathrm{JH}$ crossbreds), and the willingness of farmers to provide farm information. A total of 202,384 lactation records of cows calving between January 2007 and June 2011 were available for the analyses and consisted of
58,36 , and $6 \% \mathrm{HO}, \mathrm{JE}$, and $\mathrm{JH}$ records, respectively. Data were provided by 16 herds, ranging from 400 to 8,500 cows; 11 located in the High Plains region and 5 in north central Texas. Information was extracted from on-farm software and consisted of calving date, parity, date of dry-off, 305-d mature equivalent (305ME) milk yield, herd code, breeding data, and recorded culling reason and date. Only 1 out of 8 possible disposal (culling) codes per culled cow was reported. Culling was considered removal from the herd with any disposal code other than "dairy purposes." Live culling included all 6 disposal reasons except "died." Consequently, in the estimation of annualized culling rates, the reason "died" was considered separately. Data regarding herdrelated variables were obtained through a survey given to the farm owners or the farm veterinarians.

\section{Data Edits}

Lactation records missing parity number, calving date, or breed were removed from the data set. Records for subsequent lactations in the same cow reporting a different breed were also removed. The culling date was the last known recorded status date with the status code for culling. The number of cow-days was calculated for each individual as the number of days between the calving date and culling or death date, the subsequent calving date, or the last known event date, whichever was earlier. Cow-days for open cows were calculated as the number of days between calving and conception that resulted in a pregnancy or last known event date, whichever was earlier. Cow-days for pregnant cows were calculated as the number of days between conception and calving or last known event date, whichever was earlier.

Herd parameters were estimated from the edited lactation records. Herd milk yield (305ME) and herd size per season and year were calculated. Annualized live culling and death rates were calculated as the number of cows that were live culled or died/number of cowdays at risk $\times 365$.

\section{Events of Interest and Independent Variables}

Event of interest was reason-specific culling for 8 reasons: "low productivity," "dairy purposes," "any sickness," "breeding," "injury or sick," "mastitis," "abort," and "died." Lactation records missing a culling reason (or with an undefined character recorded) were classified under "reason not reported." Considering that a significant proportion of live culling and death occurs during early lactation (Dechow and Goodling, 2008; Dechow et al., 2012), the variables for live culling and death by 60 DIM were created for categorical analysis. 
Cow-related independent variables included parity, DIM, pregnancy status, cow's relative $305 \mathrm{ME}$ milk yield, herd, and year and season of calving. Herd-related variables considered were herd 305ME milk yield, herd size, location, type of facilities, reproductive program, replacement source and management, presence of cooling systems, and type of maternity.

To facilitate the analyses, all the variables were categorized. The distribution of the noncategorical variables was examined through the use of histograms and descriptive statistics to assist in their categorization. Independent variables were categorized as follows. Cow-relative $305 \mathrm{ME}$ milk yield was calculated as the difference from the herd mates' herd year-season average milk yield regardless of genetic group: $<-1,178 \mathrm{~kg}$ (low), $-1,178$ to $1,327 \mathrm{~kg}$ (intermediate), and $>1,327$ $\mathrm{kg}$ (high). Herd-relative 305ME milk yield was calculated as the difference from the herd year-season average: $<-676 \mathrm{~kg}$ (low), -676 to $524 \mathrm{~kg}$ (intermediate), $>524 \mathrm{~kg}$ (high). Herd size was categorized by the number of cows calving per year: $<1,069$ (small), 1,069 to 4,590 (intermediate), $>4,590$ (large). Parity was categorized as $1,2,3$, and $\geq 4$. Seasons of calving and culling were winter (January to March), spring (April to June), summer (July to September), and fall (October to December). Management-related variables were categorized as: type of facility (dry-lot, freestall, and mixed); breeding policy (heat detection, synchronization of ovulation program, natural service, and mixed); origin of replacement (purchased heifers, heifers sent to a grower farm, heifers kept in the farm, and mixed); cooling system (yes, and no); and maternity facilities (dry-lot, individual pen, and collective pen).

\section{Statistical Analysis}

Annualized live culling and death rates were estimated by categories of explanatory variables. Significant differences among categories were tested by using the Chi-square test. The distribution of reasons of disposal was analyzed by genetic group and days after calving. Considering the limited period at risk and the binary nature of the outcome variables (live culling; death), logistic regression (PROC GLIMMIX; SAS Institute Inc., Cary, NC; release 9.2) was used for the analyses of live culling by 60 DIM and death by 60 DIM, and generalized linear models were fitted to the data. Models were fitted independently for each of these 2 dependent variables to test the effect of cow- and herd-related factors and management variables, including type of facility, origin of replacement, use of cooling systems, and type of maternity on culling. Univariate analyses were used to test the inclusion of each the explanatory variables in the final models. Subsequently, the effects with a $P$-value $\leq 0.20$ were included in the multivariable analysis. The final models were tested through a backward elimination procedure with the variable breed forced into the models and herd included as the only random variable.

Hazard distributions for specific disposal reasons were calculated by parity for the overall population, stratifying the analysis by genetic group with the STRATA statement, using the actuarial method in the LIFETEST procedure of SAS. Calving was considered the origin of time in the estimation of hazard functions and cows surviving until the subsequent calving were censored at that point. Records missing a subsequent calving date or a culling event and date were considered censored at the last known event date. The dynamics of risk for reason-specific culling for each genetic group were analyzed separately.

\section{RESULTS}

\section{Distribution of Reason-Specific Culling}

Available data after edits included 202,384 lactations in 16 herds ranging from 407 to 8,773 cows calving per year during the study period and consisted of 58 (5-91\%), 36 (4-90\%), and 6\% (2-72\%) HO, JE, and JH records, respectively. Annualized live culling and death rate were 27.7 and $5.9 \%$, respectively, for the overall population. Excluding "reason not reported" (7.5\%), the primary reason for disposal across genetic groups was "low productivity" (19.4\% of all culling), followed by "died" (17.5\%), "mastitis" (13.1\%), and "injury-sick" $(10.4 \%)$.

Annualized live culling and death rates by genetic group, by parity, and up to 60 DIM are depicted in Figure 1. Overall culling rates across breeds were 30.1, 32.1 , and $35.0 \%$ for $\mathrm{JH}$ crosses, JE, and $\mathrm{HO}$, respectively. Values for overall culling increased with parity and ranged from $23.2 \%$ for $\mathrm{JH}$ crossbreds in parity 2 to $56.1 \%$ for $\mathrm{HO}$ in parity $\geq 4$. Live culling for $\mathrm{HO}$ was $29.8 \%$, followed by JH crosses $(25.8 \%)$ and JE $(24.3 \%)$. Live culling in HO increased from parity $1(22.9 \%)$ to parity $\geq 4(46.9 \%)$. However, in JE and JH crosses, live culling was higher in parity 2 than in parity 1 . Values subsequently increased in parities 3 and $\geq 4$. Conversely, annual death rate was highest for JE (7.7\%), followed by $\mathrm{HO}(5.2 \%)$ and $\mathrm{JH}$ crosses $(4.3 \%)$. Death rate increased with parity and ranged from $3 \%$ in $\mathrm{JH}$ crosses during parity 1 to $14 \%$ in JE in parity $\geq 4$. Live culling up to $60 \mathrm{~d}$ ranged from $4.1 \%$ for JH crossbreds to $6.2 \%$ for HO. Similarly, death rates up to $60 \mathrm{~d}$ ranged from $1.57 \%$ for JH crossbreds to $2.9 \%$ for JE.

The frequency distributions of annualized reasonspecific culling by genetic group are reported in Table 

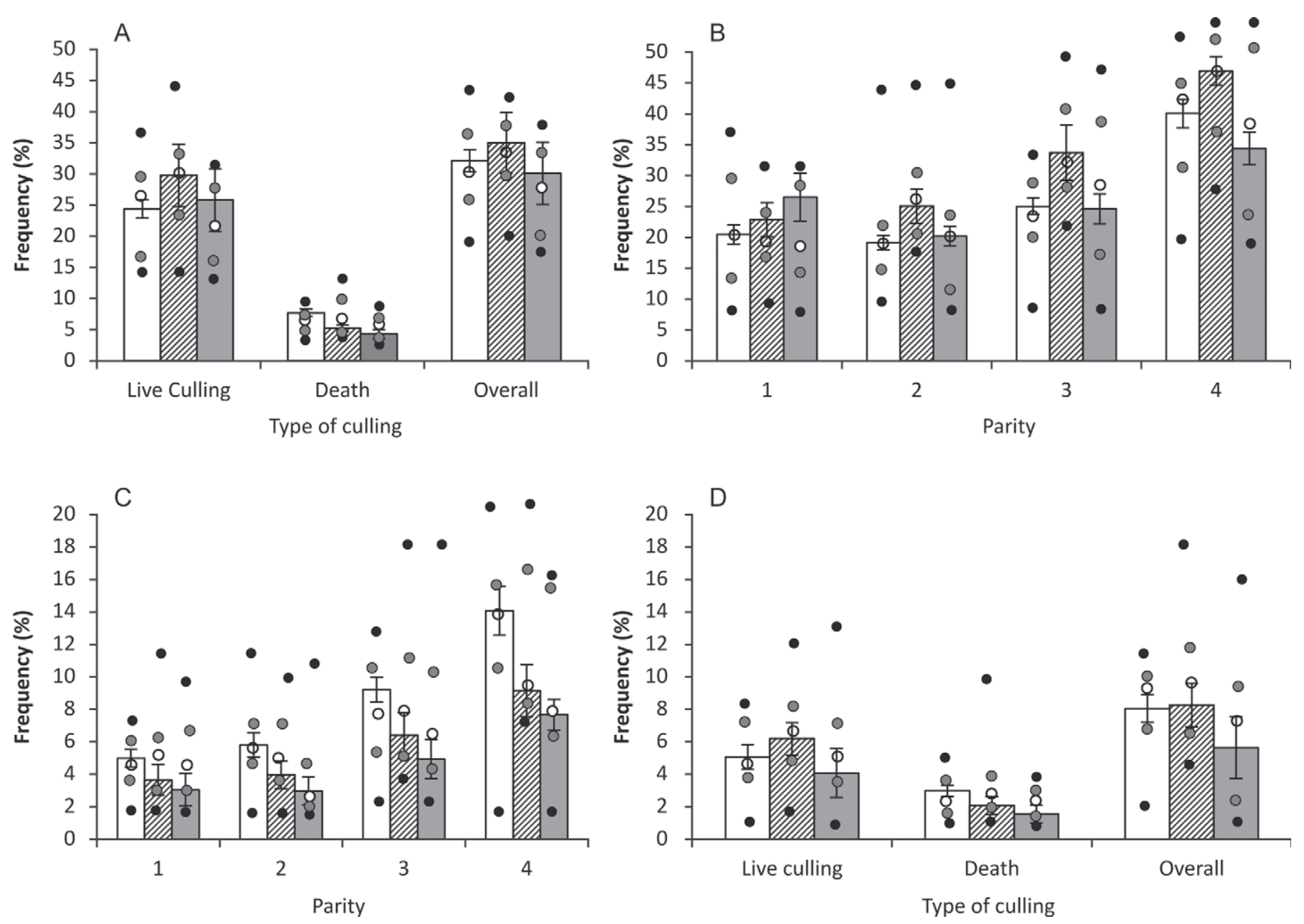

Figure 1. Frequency distribution (\%) of annualized rates for live culling, death, and overall culling (A); annualized live culling rates by parity (B); annualized death rates by parity (C); and live culling and death rates within 60 DIM (D) by genetic group. Genetic groups: Jersey (solid white bar), Holstein (slashed bar), Jersey-Holstein crosses (gray bar). Distribution of herd values: median (empty circles), lowest and highest values (black circles), first and third quartiles (gray circles).

1. Reported culling reasons are grouped as economic or biological reason (Fetrow et al. 2006). Culling due to economic reasons was higher in HO (14.4\%) compared with $\mathrm{JH}$ crosses $(7.9 \%)$ and JE (7.4\%). Likewise, HO had the largest value for biological culling (12.1\%), followed by JH crosses (10.2\%) and JE (9.2\%). Aside from "reason not reported," the most often recorded reason of disposal in JE was "died" (7.7\%). "Low productivity" was the most common reason for culling in $\mathrm{HO}(11.5 \%)$ and $\mathrm{JH}$ crosses $(6.0 \%)$.

Pregnancy had a protective effect; open cows had a 3.5 to 4.6 times greater risk for overall culling compared with pregnant cows. Low cow- and herd-relative 305ME milk yield were associated with greater risk of culling. No clear trend was observed for the association between culling and herd size or calving season (Table 2).

The distribution of culling reasons by days after calving for each genetic group is presented in Figure 2. The relative frequencies varied with stage of lactation, with the categories "low production," "died," and "breeding" having the most remarkable changes. During the first $100 \mathrm{~d}$ after calving, "died" was the primary reason for leaving the herd. Conversely, "low production" and "breeding" were the main reasons for culling after 330 d after calving.

\section{Hazard Distributions for Reason-Specific Culling}

Overall risk for culling by days after calving was highest in the first $60 \mathrm{~d}$ for the 3 genetic groups. After 300 DIM, the risk increased steadily again (Figure 3A). Changes in the risk for "low productivity" were more remarkable in HO cows, with the risk increasing notably after d 300. Similarly, the risk for "low productivity" culling increased in $\mathrm{JH}$ crosses after $400 \mathrm{~d}$. This culling category was lower and more homogenous across DIM 
Table 1. Annualized reason-specific culling rates by genetic group, grouped as economic or biological culling reason

\begin{tabular}{|c|c|c|c|c|c|c|c|c|}
\hline Item $(\%)$ & Jersey & $\mathrm{SE}$ & Holstein & $\mathrm{SE}$ & $\begin{array}{l}\text { Jersey-Holstein } \\
\text { crosses }\end{array}$ & $\mathrm{SE}$ & $\begin{array}{c}\text { Overall } \\
\text { population }\end{array}$ & $\mathrm{SE}$ \\
\hline \multicolumn{9}{|l|}{ Economic reason } \\
\hline Low productivity & 2.7 & 0.04 & 11.5 & 0.05 & 6.0 & 0.04 & 6.5 & 0.04 \\
\hline Breeding & 4.7 & 0.02 & 2.9 & 0.03 & 1.9 & 0.03 & 3.3 & 0.03 \\
\hline Total & 7.4 & & 14.4 & & 7.9 & & 9.8 & \\
\hline \multicolumn{9}{|l|}{ Biological reason } \\
\hline Any sickness & 1.9 & 0.02 & 2.9 & 0.01 & 1.2 & 0.01 & 2.0 & 0.02 \\
\hline Injury, sick & 2.9 & 0.01 & 3.7 & 0.02 & 3.6 & 0.02 & 3.5 & 0.02 \\
\hline Mastitis & 3.8 & 0.02 & 5.2 & 0.03 & 4.9 & 0.03 & 4.4 & 0.02 \\
\hline Abort & 0.6 & 0.01 & 0.3 & 0.01 & 0.5 & 0 & 0.6 & 0.01 \\
\hline Total & 9.2 & & 12.1 & & 10.2 & & 10.5 & \\
\hline Not reported & 7.9 & 0.06 & 3.3 & 0.09 & 7.7 & 0.11 & 7.5 & 0.08 \\
\hline Live culling & 24.4 & 0.04 & 29.8 & 0.09 & 25.8 & 0.1 & 27.7 & 0.08 \\
\hline Died & 7.7 & 0.01 & 5.2 & 0.02 & 4.3 & 0.02 & 5.9 & 0.02 \\
\hline Overall culling & 32.1 & 0.04 & 35.0 & 0.1 & 30.1 & 0.11 & 33.6 & 0.08 \\
\hline
\end{tabular}

in JE cows (Figure 3B). The highest risk for "any sickness" was in HO cows during early lactation. After 100 $\mathrm{d}$, the risk remained low and stable for the 3 groups (Figure 3C). The risk for "breeding" culling steadily increased after d 300, with especially high levels for JE and $\mathrm{JH}$ crosses up to d 500 (Figure 3D). The risk for "injury-sick" for the 3 groups was highest from calving to d 50 and then remained low until d 500 (Figure 3E). Culling with reasons "mastitis" and "died" were highest in the first $10 \mathrm{~d}$ after calving and decreased until d 50. "Mastitis" culling decreased more gradually with DIM, in a similar trend for the 3 genetic groups. The risk for both recorded reasons remained low until d 500
(Figures 3F and 3H). "Abort" culling was highest at the time of expected parturition for the 3 genetic groups. After 300 DIM the risk increased steadily (Figure 3G).

\section{Logistic Regression Analyses}

Estimated unadjusted odds ratio (OR) for the risk of live culling and death within $60 \mathrm{~d}$ after calving across variables of interest are presented in Table 3 . The odds of dying were higher for JE compared with $\mathrm{HO}(\mathrm{OR}=$ 1.18; $95 \% \mathrm{CI}=1.08-1.28)$. Conversely, JH crosses were in a lower risk compared with $\mathrm{HO}(\mathrm{OR}=0.79 ; 95 \% \mathrm{CI}$ $=0.71-0.87)$. However, both $\mathrm{JE}$ and $\mathrm{JH}$ crosses had

Table 2. Annualized overall culling rate by genetic group and subgroup

\begin{tabular}{|c|c|c|c|c|c|c|}
\hline Subgroup (\%) & Jersey & $\mathrm{SE}$ & Holstein & $\mathrm{SE}$ & $\begin{array}{l}\text { Jersey-Holstein } \\
\text { crosses }\end{array}$ & $\mathrm{SE}$ \\
\hline \multicolumn{7}{|l|}{ Pregnant } \\
\hline Yes & $12.6^{\mathrm{a}}$ & 3.5 & $15.0^{\mathrm{a}}$ & 11.6 & $14.6^{\mathrm{a}}$ & 12.0 \\
\hline No & $58.7^{\mathrm{b}}$ & 12.3 & $52.2^{\mathrm{b}}$ & 15.4 & $60.2^{\mathrm{b}}$ & 15.9 \\
\hline \multicolumn{7}{|c|}{ Cow-relative $305 \mathrm{ME}^{1}$ milk yield } \\
\hline$<-1,178$ & $56.9^{\mathrm{c}}$ & 10.8 & $51.9^{\mathrm{c}}$ & 10.9 & $63.9^{\mathrm{c}}$ & 14.4 \\
\hline$-1,178$ to 1,327 & $17.5^{\mathrm{b}}$ & 3.6 & $24.5^{\mathrm{b}}$ & 10.6 & $17.8^{\mathrm{a}}$ & 11.2 \\
\hline$>1,327$ & $11.3^{\mathrm{a}}$ & 3.3 & $16.2^{\mathrm{a}}$ & 13.4 & $42.4^{\mathrm{b}}$ & 12.2 \\
\hline \multicolumn{7}{|c|}{ Herd-relative $305 \mathrm{ME}$ milk yield } \\
\hline$<-676$ & $41.1^{\mathrm{c}}$ & 21.8 & $61.7^{\mathrm{c}}$ & 21.0 & $75.8^{\mathrm{c}}$ & 27.6 \\
\hline-676 to 524 & $24.4^{\mathrm{b}}$ & 4.4 & $28.1^{\mathrm{b}}$ & 16.8 & $24.7^{\mathrm{b}}$ & 15.3 \\
\hline$>524$ & $21.0^{\mathrm{a}}$ & 10.3 & $27.1^{\mathrm{a}}$ & 9.9 & $22.5^{\mathrm{a}}$ & 18.3 \\
\hline \multicolumn{7}{|l|}{ Herd size } \\
\hline$<1,069$ & $27.0^{\mathrm{a}}$ & 11.0 & $42.5^{\mathrm{c}}$ & 22.7 & $22.1^{\mathrm{a}}$ & 24.5 \\
\hline 1,069 to 4,590 & $33.0^{\mathrm{b}}$ & 6.7 & $34.4^{\mathrm{a}}$ & 6.9 & $33.8^{\mathrm{c}}$ & 11.7 \\
\hline$>4,590$ & $33.6^{\mathrm{c}}$ & 1.0 & $36.3^{\mathrm{b}}$ & 2.0 & $29.6^{\mathrm{b}}$ & 1.0 \\
\hline \multicolumn{7}{|l|}{ Calving season } \\
\hline Winter & $32.9^{\mathrm{a}}$ & 4.4 & $37.6^{\mathrm{c}}$ & 11.4 & $31.2^{\mathrm{d}}$ & 12.2 \\
\hline Spring & $30.3^{\mathrm{b}}$ & 4.0 & $34.0^{\mathrm{a}}$ & 8.7 & $29.7^{\mathrm{b}}$ & 12.5 \\
\hline Summer & $32.5^{\mathrm{c}}$ & 4.6 & $34.6^{\mathrm{b}}$ & 9.7 & $30.5^{\mathrm{c}}$ & 10.1 \\
\hline Fall & $32.7^{\mathrm{d}}$ & 3.9 & $34.1^{\mathrm{a}}$ & 9.9 & $29.1^{\mathrm{a}}$ & 11.7 \\
\hline
\end{tabular}

$\overline{{ }^{a-d}}$ Different letters in the same column within subgroup indicate significant differences between categories in the subgroup $(P \leq 0.01)$.

${ }^{1} 305 \mathrm{ME}=305$-d mature equivalent. 

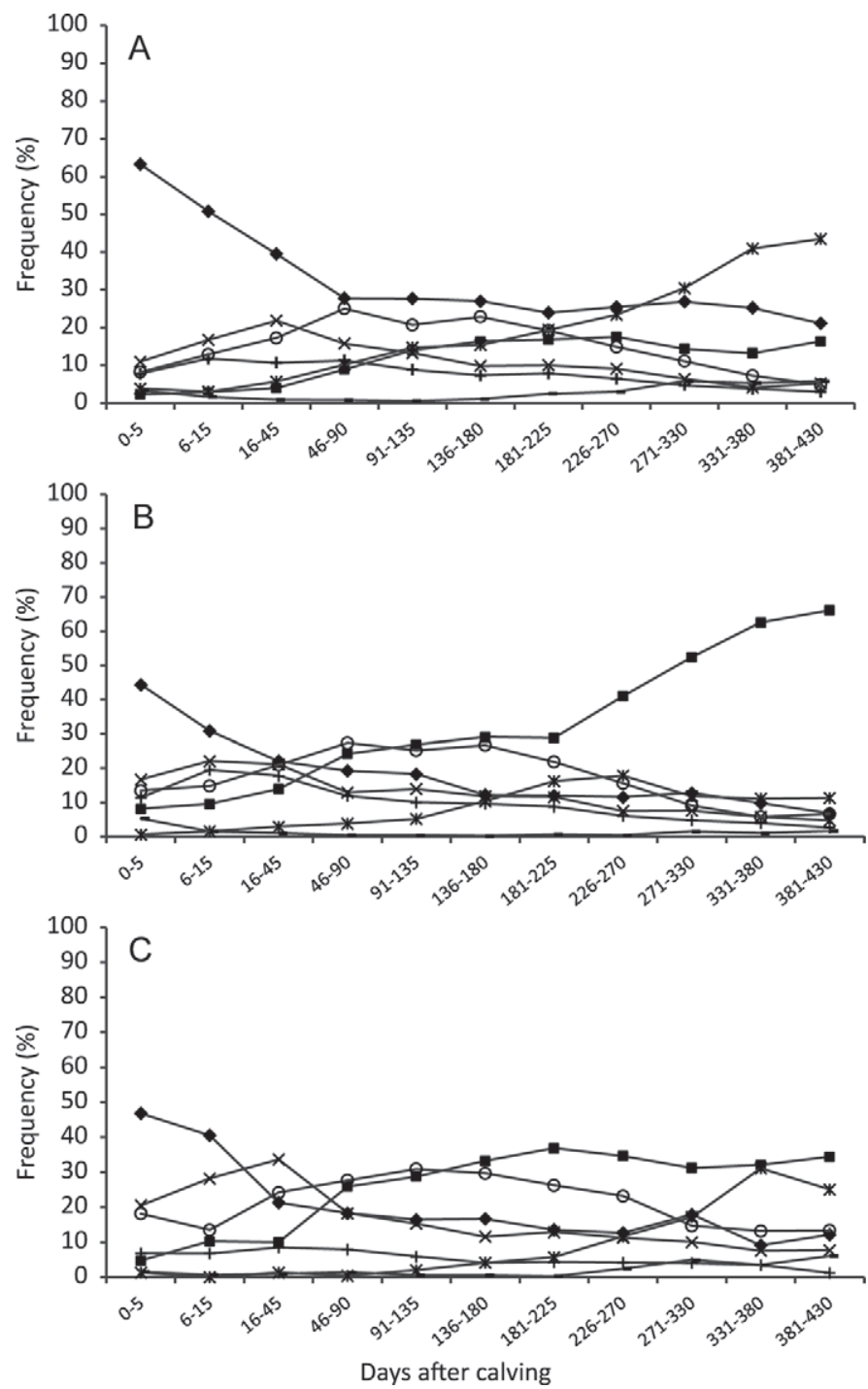

Figure 2. Distribution (\%) of culling reasons by days after calving for each genetic group (each day is 100\%): Jersey (A), Holstein (B), Jersey-Holstein crosses (C). Reasons: any sickness $(+)$, low productivity $(\mathbf{\square})$, breeding $(*)$, injury or sick $(\times)$, mastitis $(O)$, abort $(\boldsymbol{-})$, and died $(\diamond)$.

lower odds of live culling compared with $\mathrm{HO}$ cows (OR $=0.78$ and $0.65 ; 95 \% \mathrm{CI}=0.74-0.82$ and $0.61-0.69$, respectively).

Cow variables significantly associated with the risk of dying were cow-relative 305ME milk yield, parity, and season of calving (winter vs. fall). Significant herdrelated variables included herd-relative $305 \mathrm{ME}$ milk yield, herd size, type of facility, origin of replacement, use of cooling systems, and type of maternity. The same variables plus geographic location were significantly associated with live culling within $60 \mathrm{~d}$ after calving.

The final multivariate model indicated that cow variables significantly associated with the risk of death within $60 \mathrm{~d}$ after calving were cow-relative $305 \mathrm{ME}$ milk yield, parity, and season of calving (Table 4). Contrary to the outcome from the univariate analyses, the risk of death was not associated with genetic group. The only herd-related variables that remained significant were herd size and origin of replacement. Regarding the risk of live culling within $60 \mathrm{~d}$ after calving, significant cow variables were included the same variables reported in the univariate analysis, with the exception of geographical location.

\section{DISCUSSION}

The present study described dairy producers' recorded primary reasons for culling in large multibreed herds in Texas. Overall, annualized live culling and death rates across genetic groups were 27.7 and $5.9 \%$, respectively. Considering that this estimation does not include the reason "dairy purposes," these values are within the reported ranges (Smith et al., 2000; Hadley et al., 2006; Miller et al., 2008; Pinedo et al., 2010). Interestingly, $\mathrm{HO}$ had the highest culling due to economic reasons, about 6 percentile points higher than $\mathrm{JH}$ crosses and JE. This difference was due to a higher value for "low productivity" culling in HO cows (Table 1). However, it is probable that some of the records indicating low productivity may have had concurrent biological reasons for disposal, such as disease or low reproductive performance. In contrast, the difference among breeds for biological culling was within a range of 2.9 percentile points, suggesting that the disadvantage for overall survival in HO compared with JE and $\mathrm{JH}$ crosses was mostly related to economic decisions made by the farmers.

Live culling was greater for $\mathrm{HO}$, followed by $\mathrm{JH}$ crosses and JE. Likewise, both JE and JH crosses had lower odds of live culling within 60 DIM compared with HO cows. Hare et al. (2006) reported higher survival rates for JE compared with $\mathrm{HO}$, with differences ranging from 1.3 to $7.4 \%$ for parity 1 and parity 3 , respectively. Similarly, a large-scale study analyzing 7 regions in the United States indicated that survival to 5 yr was higher for JE cows than HO (Garcia-Peniche et al., 2006). When overall culling rates where estimated for $\mathrm{HO}$ and JE herds in the northeast and the Midwest regions in the United States, a difference of 4.7 percentile points in survival was determined in favor of JE cows (Hadley et al., 2006). In contrast, in the current study, death rate was greatest for $\mathrm{JE}$, followed by $\mathrm{HO}$ and $\mathrm{JH}$ crossbred cows. Contrary to our results, Miller et al. (2008) reported no differences when within-herd breed mortality was compared between $\mathrm{HO}$ and JE, whereas an analysis of Danish cattle indicated a higher death rate for JE than HO (Thomsen et al., 2004). The high 

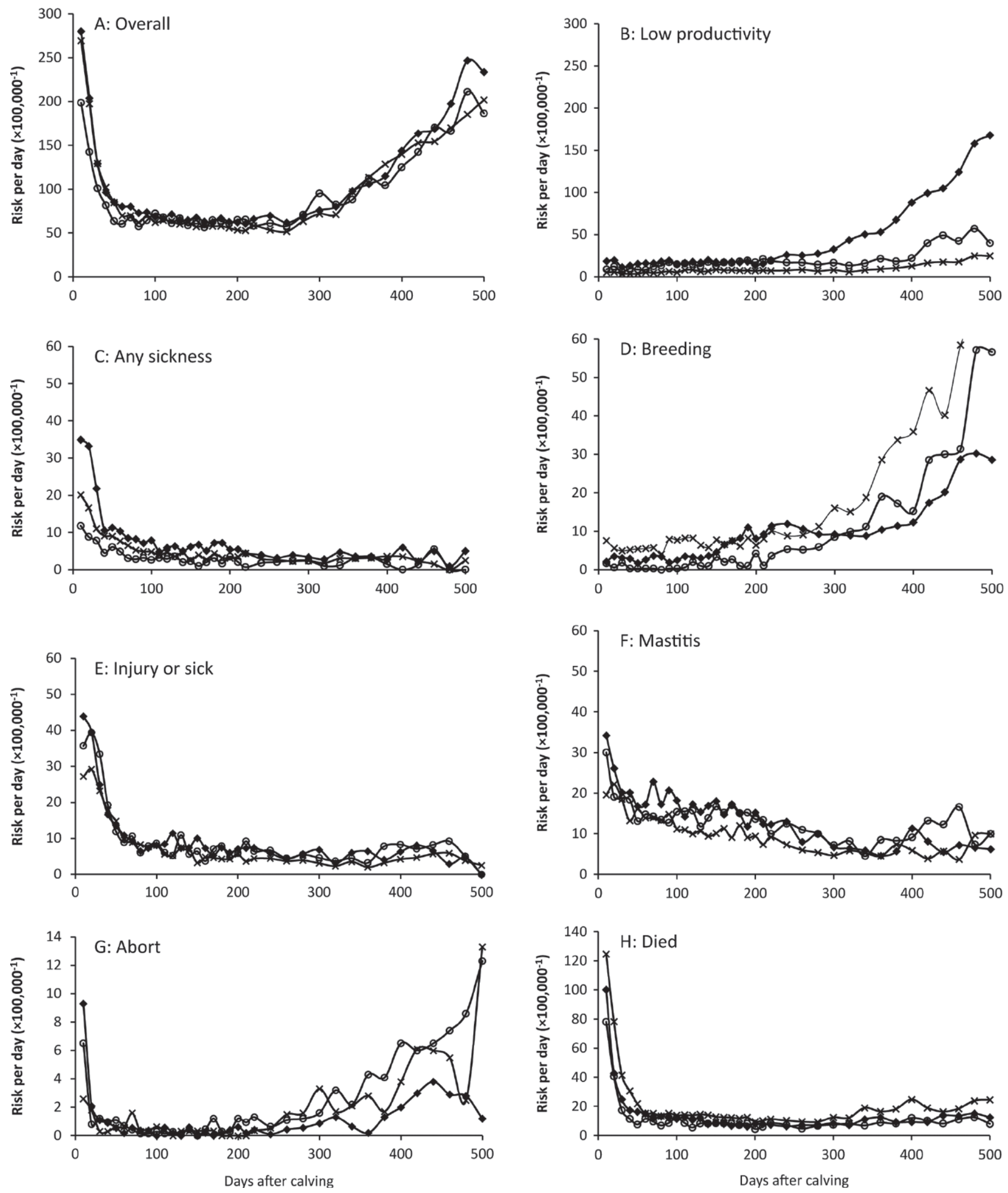

Figure 3. Distribution of culling risk $\left(\times 100,000^{-1}\right)$ by days after calving for each genetic group: Jersey $(\times)$, Holstein $(\bullet)$, and JerseyHolstein crosses $(\mathrm{O})$. Reasons: overall $(\mathrm{A})$, low productivity $(\mathrm{B})$, any sickness (C), breeding (D), injury or sick (E), mastitis (F), abort (G), died (H; scales vary for y-axis). 
Table 3. Unadjusted odds ratios (OR) and confidence interval (CI) for risk of death and live culling within $60 \mathrm{~d}$ after calving by multiple variables

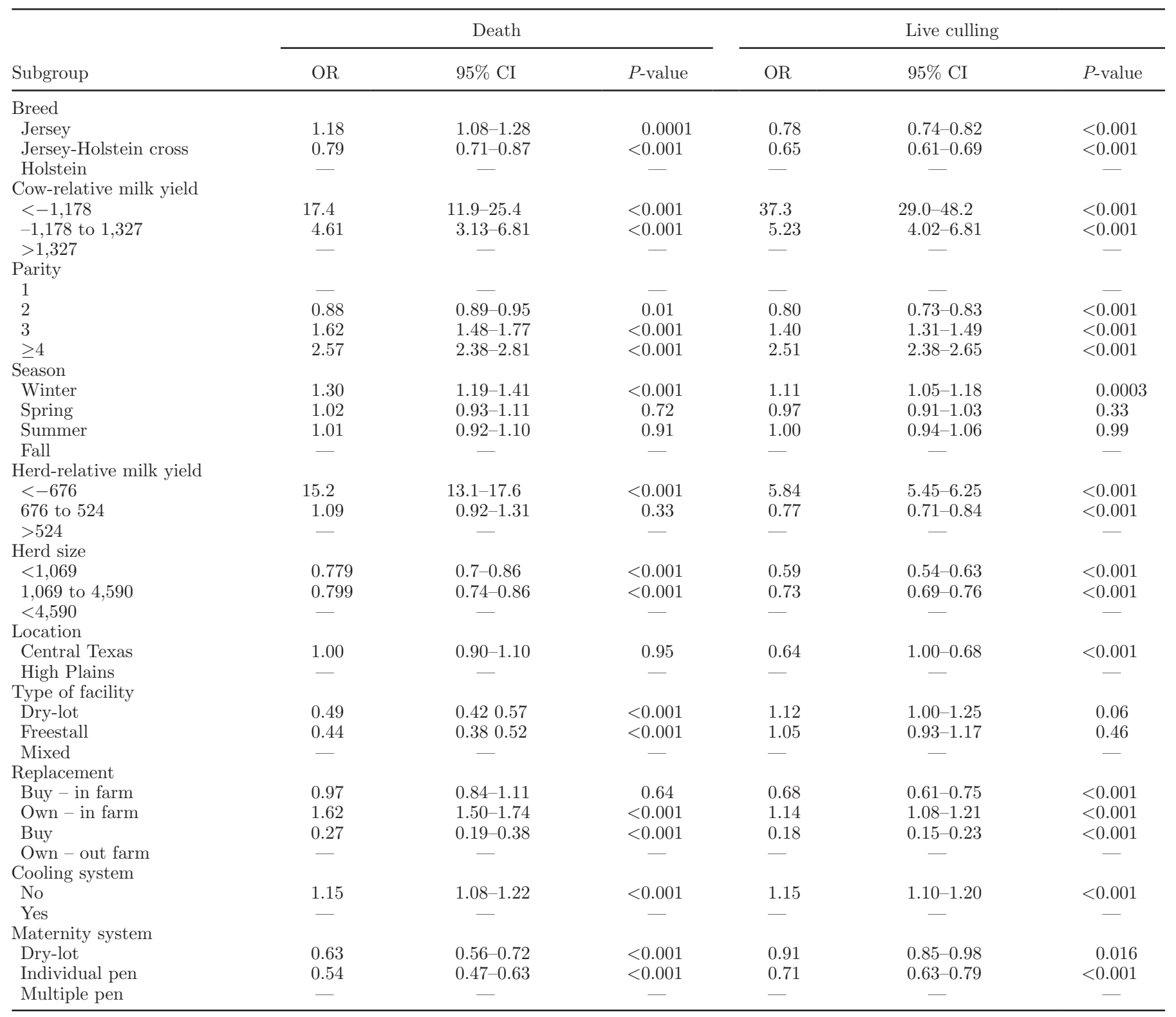

death rate within 60 DIM observed in JE in the current study may be explained in part by potential metabolic disorders during early lactation, such as hypocalcemia, more common in this group and imposing a management challenge, as some of the participant herds were transitioning from $\mathrm{HO}$ to $\mathrm{JH}$ or JE during the study period.

Aside from "reason not reported" the main reason for culling across breed was "low production" followed by "died." When genetic group was considered, "low production" was the most frequently recorded reason of culling for HO. Notably, "reason not reported" was the largest category for $\mathrm{JE}$ and $\mathrm{JH}$ crosses, followed by "died" in JE and "low productivity" in JH cows. No evident reason was observed for this level of missing information, which adds a degree of uncertainty to the overall reason-specific culling analysis. Moreover, it is expected that some culling may be associated with an additional problems besides the reported reason, a potential case being disease resulting in low productivity.

The current results are in partial agreement with data reported by Hadley et al. (2006), where "injury/other" was the primary reported reason for culling, followed by "reproduction" and "low production." Two studies 
Table 4. Multivariate logistic regression for risk of death and live culling within $60 \mathrm{~d}$ after calving by multiple variables ${ }^{1}$

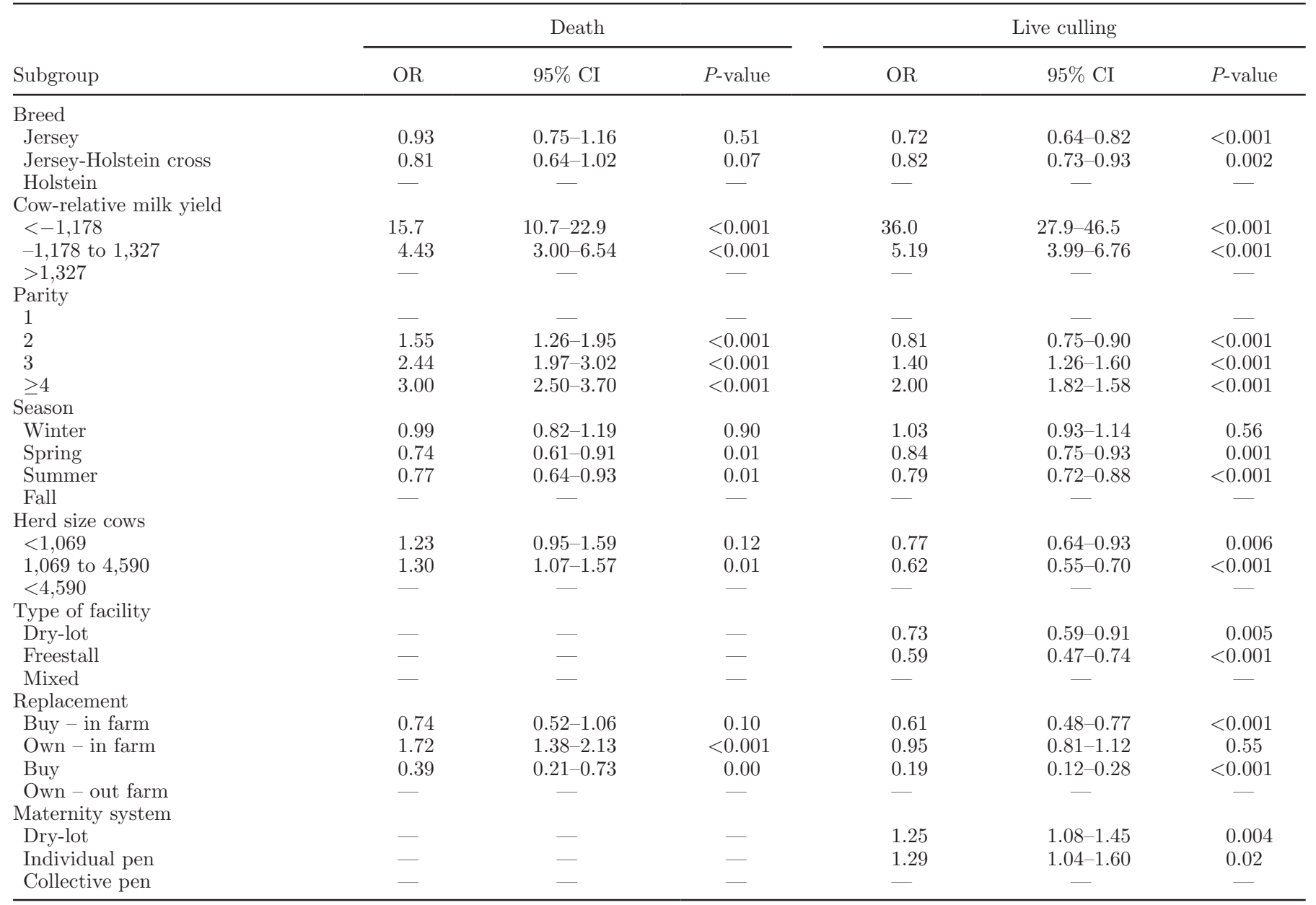

${ }^{1}$ Only breed and significant subgroups are presented. OR $=$ odds ratio.

conducted in New York are also in partial agreement with the present results, in that they indicated "low production," "reproduction," and "udder problems" as the primary reported reasons for culling (Van Vleck and Norman, 1972; Milian-Suazo et al., 1988). Similarly, Bascom and Young (1998) reported "reproduction" as the primary disposal reason, followed by "low production" and "mastitis." In a more recent study analyzing Holstein cows in herds enrolled in the DHI program, the primary reason for disposal was "died," followed by "reproduction," "injury/other," "low production," and "mastitis" (Pinedo et al., 2010).

A limitation of the current study was that some of the participating herds were part of a group of farms under the same ownership, allowing cow movements among farms. Such displacements may have resulted in misclassification of culling reasons. Among other potential errors, some of the removal reasons due to "dairy purposes" may have been reported, reflecting the concurrent cause motivating the management decision behind the movement. This may explain, in part, the high values of "low productivity" culling in HO in some of the study herds. As the number of herds analyzed was limited, misreporting is a potential problem.

As previously reported (van Arendonk and Dijkhuizen, 1985; Thomsen et al., 2004; Miller et al., 2008), cows in a higher parity were at a greater risk $(P<$ 0.001; Figure 1) for overall culling (annualized culling rates from $23.2 \%$ for parity 1 in $\mathrm{JH}$ crosses to $56.1 \%$ for parity $\geq 4$ in $\mathrm{HO}$ ). As expected, pregnancy had a protective effect against culling. Pregnant cows had a lower annualized live culling rate $(15.1 \%)$ compared with open cows (60.2\%). The strong association between reproductive performance and cow survival has been stated (Rajala-Schultz and Gröhn, 1999; Schneider et al., 2007). Cows that required more services per conception, had an interval between calving to first service greater than $90 \mathrm{~d}$, or had increased days open, have been shown to be at greater risk of being culled (Milian-Suazo et al., 1989; Sewalem et al., 2008). 
In agreement with previous studies, overall culling rates were greater for low-producing cows in all the genetic groups (Miller et al., 2008; Pinedo et al., 2010). Also, in conformity with our results, a similar trend for higher culling in herds with lower milk production has been reported (Smith et al., 2000).

Culling risks are affected by physiological processes, such as calving, lactation, energy balance, reproduction, and aging. A critical time for survival is the transition period, where cows experience a series of notorious challenges, and most of the metabolic diseases occur (Goff and Horst, 1997). The greatest risk of culling has been reported in early lactation and after $420 \mathrm{~d}$ postcalving (Fetrow et al., 2006), with culling rates by 60 DIM close to $8 \%$ (Dechow and Goodling, 2008). The high occurrence of live culling and death in early lactation in the current study is in agreement with previous reports (Hadley et al., 2006; Dechow and Goodling, 2008), where "died" was the most common disposal code up to $60 \mathrm{~d}$ after calving. As expected, culling risk for "any sickness" and "injury sick" had the highest values during early lactation. Conversely, specific reasons contributing the most to advanced lactation culling were "low productivity," "breeding," and "abort," as cows were likely diagnosed open during pregnancy check at dry-off. Multiple herd variables were significantly associated with the risk of live culling and death within $60 \mathrm{~d}$ after calving.

\section{CONCLUSIONS}

Overall, JH crossbred cows had the lowest annualized culling rate, followed by JE and then HO. The dynamics of reason-specific culling were dependent on genetic group, stage of lactation, parity, milk yield, and herd characteristics. Early lactation was a critical period for "died," "any sickness," and "injury-sick" culling. The risk increased with days after calving for "reproduction" and, for HO, "low productivity" culling.

\section{ACKNOWLEDGMENTS}

The authors thank the American Jersey Cattle Association (Reynoldsburg, $\mathrm{OH}$ ) for financial support provided to help fund this study. The dairy producers are acknowledged for supplying the data used in this study.

\section{REFERENCES}

Bascom, S. S., and A. J. Young. 1998. A summary of the reasons why farmers cull cows. J. Dairy Sci. 81:2299-2305.

Dechow, C. D., and R. C. Goodling. 2008. Mortality, culling by sixty days in milk, and production profiles in high- and low-survival Pennsylvania herds. J. Dairy Sci. 91:4630-4639.
Dechow, C. D., R. C. Goodling, and S. P. Rhode. 2012. The effect of sire selection on cow mortality and early lactation culling in adverse and favorable cow survival environments. Prev. Vet. Med. 103:228-233.

Fetrow, J., K. V. Nordlund, and H. D. Norman. 2006. Invited review: Culling: Nomenclature, definitions, and recommendations. J. Dairy Sci. 89:1896-1905.

Garcia-Peniche, T. B., B. G. Cassell, and I. Misztal. 2006. Effects of breed and region on longevity traits through five years of age in Brown Swiss, Holstein, and Jersey cows in the United States. J. Dairy Sci. 89:3672-3680.

Goff, J. P., and R. L. Horst. 1997. Physiological changes at parturition and their relationship to metabolic disorders. J. Dairy Sci. 80:1260-1268

Hadley, G. L., C. A. Wolf, and S. B. Harsh. 2006. Dairy cattle culling patterns, explanations, and implications. J. Dairy Sci. 89:22862296.

Hare, E., H. D. Norman, and J. R. Wright. 2006. Survival rates and productive herd life of dairy cattle in the United States. J. Dairy Sci. 89:3713-3720.

Heins, B. J., L. B. Hansen, A. R. Hazel, A. J. Seykora, D. G. Johnson, and J. G. Linn. 2012. Short communication: Jersey $\times$ Holstein crossbreds compared with pure Holsteins for body weight, body condition score, fertility, and survival during the first three lactations. J. Dairy Sci. 95:4130-4135.

McConnel, C. S., J. E. Lombard, B. A. Wagner, and F. B. Garry. 2008. Evaluation of factors associated with increased dairy cow mortality on United States dairy operations. J. Dairy Sci. 91:1423-1432.

Milian-Suazo, F., H. N. Erb, and R. D. Smith. 1988. Descriptive epidemiology of culling in dairy cows from 34 herds in New York State. Prev. Vet. Med. 6:243-251.

Milian-Suazo, F., H. N. Erb, and R. D. Smith. 1989. Risk factors for reason-specific culling of dairy cows. Prev. Vet. Med. 7:19-29.

Miller, R. H., M. T. Kuhn, H. D. Norman, and J. R. Wright. 2008 Death loses for lactating cows in herds enrolled in dairy herd improvement test plans. J. Dairy Sci. 91:3710-3715.

Pinedo, P. J., A. De Vries, and D. W. Webb. 2010. Dynamics of culling risk with disposal codes reported by DHI dairy herds. J. Dairy Sci. 93:2250-2261.

Rajala-Schultz, P. J., and Y. T. Gröhn. 1999. Culling of dairy cows. Part III. Effect of diseases, pregnancy status and milk yield on culling in Finnish Ayrshire cows. Prev. Vet. Med. 41:295-309.

Schneider, M. del P., E. Strandberg, U. Emanuelson, K. Grandhinson, and A. Roth. 2007. The effect of veterinary-treated clinical mastitis and pregnancy status on culling in Swedish dairy cows. Prev. Vet. Med. 80:179-192

Sewalem, A., F. Miglior, G. J. Kistemaker, P. Sullivan, and B. J. van Doormaal. 2008. Relationship between reproduction traits and functional longevity in Canadian dairy cattle. J. Dairy Sci. 91:1660-1668.

Smith, J. W., L. O. Ely, and A. M. Chapa. 2000. Effect of region, herd size, and milk production on reasons cows leave the herd. J. Dairy Sci. 83:2980-2987.

Thomsen, P. T., and H. Houe. 2006. Dairy cow mortality. A review. Vet. Q. 28:122-129.

Thomsen, P. T., A. M. Kjeldsen, J. T. Sørensen, and H. Houe. 2004. Mortality (including euthanasia) among Danish dairy cows (19902001). Prev. Vet. Med. 62:19-33.

van Arendonk, J. A. M., and A. A. Dijkhuizen. 1985. Studies on the replacement policies in dairy cattle. III. Influence of variation in reproduction and production. Livest. Prod. Sci. 13:333-349.

Van Vleck, L. D., and H. D. Norman. 1972. Association of type traits with reasons for disposal. J. Dairy Sci. 55:1698-1705.

Weigel, K. A., R. W. Palmer, and D. Z. Caraviello. 2003. Investigation of factors affecting voluntary and involuntary culling in expanding dairy herds in Wisconsin using survival analysis. J. Dairy Sci. 86:1482-1486. 